\title{
Potential Predictive Markers in Protocol Biopsies for Premature Renal Graft Loss
}

\author{
Ivo Matl ${ }^{a}$ Petra Hribovab Eva Honsovac Irena Brabcovab Ondrej Viklicky ${ }^{\mathrm{a}}{ }^{\mathrm{b}}$

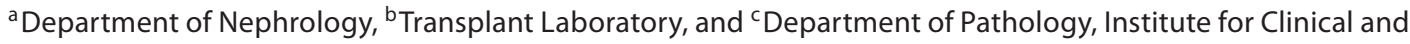 \\ Experimental Medicine, Prague, Czech Republic
}

\section{Key Words}

Subclinical rejection - Borderline changes · Gene

expression $\cdot$ Chemokines $\cdot$ Cytokines

\begin{abstract}
Background/Aims: Protocol biopsies offer new possibilities to predict kidney allograft outcome. The aim of this study was to find clinical, laboratory, morphological and molecular predictors of short-term renal graft survival. Methods: Three-month protocol kidney graft biopsy was carried out on 257 patients. The real-time RT-PCR was used to identify intragraft mRNA expression of several cytokines and chemokines and predictive statistics was performed to find markers connected with the risk of premature graft failure. Results: Compared to patients with normal morphology at 3 months, patients with subclinical rejection including borderline changes had experienced more frequent $(p<0.001)$ acute rejections before 3-month biopsy, serum creatinine $\geq 170 \mu \mathrm{mol} / \mathrm{l}(\mathrm{p}<0.01)$, and higher intrarenal expression of RANTES, IP-10 ( $p<0.001), C 3, C D 3$, IgJ $(p<0.01)$ and CD20 $(p<0.05)$. There was a significant correlation between subclinical rejection and the occurrence of late acute rejection and graft failure at the first year after transplantation. Moreover, higher RANTES and IP-10 expressions in subclinical rejection predicted graft loss at one year after transplantation in the univariate analysis. Conclusions: Patients with sub-
\end{abstract}

clinical rejection including borderline changes in 3-month biopsy and particularly those with higher intrarenal expression of RANTES and IP-10 mRNA were found to be at risk for premature kidney graft loss. Copyright $\odot 2010$ S. Karger AG, Basel

\section{Introduction}

Over the past 10 years, protocol biopsies have become a standard procedure in many transplant centers. Subclinical rejection, defined as morphologically found rejections without clinical suspicion, may represent a risk for graft failure [1-3]. Besides poor organ quality, extended ischemia/reperfusion injury, drugs nephrotoxicity or hypertension, mainly alloantigen-driven processes such as acute, subclinical or chronic rejections represent the major risks for kidney graft failure [4-6]. Infiltrating cells producing a broad spectrum of cytokines, chemokines and growth factors have been frequently found within the rejected allografts [7-9].

Previously, we found that a higher mRNA expression of transforming growth factor- $\beta 1$ (TGF- $\beta 1$ ) and monocyte chemotactic protein 1 (MCP-1) in case biopsies with allograft nephropathy later after transplantation may help to identify those patients at risk for graft failure [10, 11]. Recently, we identified molecular phenotypical traits

\section{KARGER \\ Fax +4161306 1234 E-Mail karger@karger.ch} www.karger.com

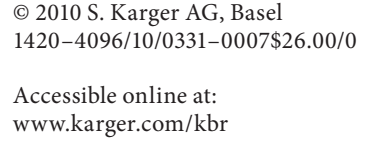

Ivo Matl, MD, PhD

Department of Nephrology

Vídeňská 1958/9

CZ-140 21 Prague 4 (Czech Republic)

Tel. +420 26136 4110,Fax +4206136 3168, E-Mail ivo.matl@ikem.cz 
of early acute rejection that predict prognosis of renal allograft [12]. Molecular signatures of acute rejection and allograft nephropathy may identify grafts at risk allowing modifying the therapy in such patients. We wonder whether besides traditional markers such as creatinine and morphology, molecular traits of subclinical rejection may help to identify grafts at risk of premature failure.

To describe the potential of such risk factors, we evaluated the patterns of intrarenal expression of several genes associated with B cell- and T cell-mediated inflammation and rejection in a large cohort of 3-month protocol biopsies and correlated it with clinical and laboratory findings and 12-month kidney graft outcome.

\section{Materials and Methods}

\section{Patient Population}

A total of 257 patients with stable graft function (3 stable values of serum creatinine (S-Cr) prior to graft biopsy) at 3 months after kidney transplantation were prospectively enrolled into the study. Patients were treated by triple-drug immunosuppression based on cyclosporine-A $(n=47)$, tacrolimus $(n=189)$, along with mycophenolate mofetil and steroids. Twenty-one patients were treated by a drug combination based on sirolimus or everolimus. 51 patients with panel reactive antibodies (PRA) $\geq 50 \%$ and/or recipients of second or third grafts received ATG induction. Twenty-four living donor graft recipients had induction with daclizumab. Demographic data are presented in table 1 . All patients with subclinical rejection (SAR), and 11/15 patients with diagnosis of borderline changes $(\mathrm{BL})$ in protocol biopsy were treated with methylprednisolone.

All patients signed informed consent with the protocol biopsy prior to their inclusion in the study. The study protocol was approved by the Ethics Committee of the Institute for Clinical and Experimental Medicine in Prague.

\section{Histology}

Protocol kidney graft biopsy was performed under ultrasound guidance using a 14-gauge gun. Samples were processed by standard paraffin technique and stained according to our laboratory protocol. All samples were tested by immunofluorescence or immunohistochemical procedures for $\mathrm{C} 4 \mathrm{~d}$ presence as a sign of antibody-mediated rejection. Histomorphological changes were graded according to the Banff updated classification $[13,14]$. The diagnosis of drug toxicity was mostly based on the finding of insudative arteriolopathy. Small portions of renal tissue from the cortex were placed into tissue storage reagent RNAlater ${ }^{\mathrm{TM}}$ (Sigma, Mo., USA) immediately after biopsy and stored at $-20^{\circ} \mathrm{C}$ for further gene expression analysis.

\section{RNA Isolation and Real-Time Quantitative RT-PCR}

Gene expression was analyzed in 163 protocol biopsies from the above-described cohort of patients. The renal tissue was homogenized; total RNA was extracted using a RNA Blue (Top-Bio, Czech Republic) and reverse transcribed into complementary DNA (cDNA), using the SuperScript ${ }^{\mathrm{TM}}$ II Reverse Transcriptase
Table 1. Demographics

\begin{tabular}{lcc}
\hline & $\mathrm{n}$ & $\%$ \\
\hline Patients & 257 & 100 \\
Men/women & $160 / 97$ & $62 / 38$ \\
Age, years & $51.8 \pm 12.4$ & \\
Cause of renal failure & & \\
$\quad$ Glomerulonephritis & 88 & 34.2 \\
$\quad$ Tubulointerstitial nephritis & 49 & 19.1 \\
$\quad$ Polycystic kidney & 33 & 12.8 \\
$\quad$ Nephrosclerosis & 34 & 13.2 \\
$\quad 16$ & 6.2 \\
$\quad$ Diabetic nephropathy & 37 & 14.4 \\
Others & $94.5 \pm 9.9$ & \\
$\quad$ I. Tx & 202 & 78.6 \\
$\quad$ II. Tx & 27 & 10.5 \\
$\quad$ III. Tx & 4 & 1.6 \\
$\quad$ LRD & 24 & 9.3 \\
PRA $\geq 50 \%$ & 30 & 11.9 \\
Patients with rejection before PB & 88 & 34.2 \\
\hline
\end{tabular}

$\mathrm{Tx}=$ Transplantation; $\mathrm{LRD}=$ living related donor

(Invitrogen, Calif., USA). cDNA was amplified by real-time quantitative polymerase chain reaction (PCR) $\left(\right.$ TaqMan $^{\mathrm{TM}}$, 7300 Real Time PCR Systems, Applied Biosystems, Calif., USA) using commercial primers and fluorogenic probes. Samples were tested for genomic DNA contamination, and if tested positive, were excluded from the study. Gene expressions of the following markers were analyzed: cytokine TGF- $\beta 1$, chemokines like MCP-1, RANTES (CCL5), and interferon- $\gamma$-inducible protein 10 (IP-10), for quantifying $\mathrm{T} / \mathrm{B} /$ plasma cell infiltration the markers CD3, CD20 and immunoglobulin J (IgJ), respectively, heme oxygenase-1 (HMOX1) as cytoprotective stress protein, and C3 complement component. Specific gene expression was calculated relative to that of the housekeeping gene HPRT and the calibrator sample (comparative threshold cycle method $\left(2^{-\Delta \Delta c_{\mathrm{T}}}\right)$ : RQ software, Applied Biosystems, Calif., USA) and it was expressed as relative quantity (RQ).

\section{Statistical Analysis}

Results are expressed as the mean \pm SD. For comparison of the means and determination of differences between two groups, Student's t test, Mann-Whitney test, ANOVA for more than two groups and $\chi^{2}$ test were used. Differences were considered significant if $\mathrm{p}<0.05$. ROC curve analysis of S-Cr was used to discriminate the probability of normal findings from SAR and BL. Logistic regression was used to find the independent predictors of SAR and BL. The prognostic variables studied included: donor age, panel reactive antibodies (PRA), acute rejections prior to protocol biopsy, and $\mathrm{S}-\mathrm{Cr}$ at the time of protocol biopsy. The differences in gene expression patterns were analyzed by the KruskalWallis test. The correlations between genes expressions were analyzed using the Spearman-rank correlation test. The 75th percentile of relative quantity (RQ value) in SAR + BL was con- 
sidered as the cut-off value for low and high intra-renal gene expression. Multivariate logistic regression analysis was used to identify the variables associated with the risk of graft failure. Variables (RANTES gene expression, IP-10 gene expression, donor age, MDRD at the time of biopsy and the type of immunosuppressive regimen) were selected from a univariate model.

\section{Results}

\section{Histomorphologic Findings}

Only 3 of 257 samples were nonrepresentative enough for histomorphological assessment. Subclinical acute rejection (SAR) was found in 17 patients (6.6\%), and borderline changes (BL) in 15 (5.8\%). Pooled SAR + BL was present in $12.4 \%$ of the patients. Interstitial fibrosis/tubular atrophy (IF/TA) was diagnosed in 25 samples (9.7\%), drug toxicity in 33 (12.8\%). Among 'others' (31 samples, $12.1 \%)$, acute tubular necrosis, glomerulopathies, and BK nephropathy were included. In 8 cases (3\%), accompanying positivity of $\mathrm{C} 4 \mathrm{~d}$ in peritubular capillaries as a sign of antibody-mediated rejection was detected. In 4/8 patients, the actual cross-match was positive, but none of the patients was treated as acute humoral rejection since they previously received specific antirejection therapy. 133 samples had a normal finding (51.7\%).

\section{Immunosuppressive Regimens and Histomorphology} at 3-Month Biopsy

In patients treated with a cyclosporine-A-based regimen, 20 (42.6\%) had normal findings in protocol biopsy, $1(2.1 \%)$ had SAR, and $5(10.6 \%)$ had BL. In patients with tacrolimus-based regimen, 104 had a normal finding (55.3), 15 (8\%) had SAR, and 9 (4.8\%) had BL. There was no statistically significant difference in SAR, BL, and $\mathrm{SAR}+\mathrm{BL}$ prevalence between patients treated with cyclosporine-A-based and tacrolimus-based regimens.

\section{Acute Rejections prior to Protocol Biopsy}

Eighty-eight patients (31.1\%) had acute rejection in the course of the first 3 months post-transplant. Incidence of acute rejection was significantly higher $(\mathrm{p}<0.001)$ in patients with SAR $(n=15,88.2 \%)$ and BL $(n=12,80 \%)$ compared to patients with normal finding in protocol biopsy ( $\mathrm{n}=37,27.8 \%)$.

\section{Serum Creatinine (fig. 1)}

The mean value of S-Cr in patients with normal finding was $127.7 \pm 27.8 \mu \mathrm{mol} / \mathrm{l}$. In the subgroup with SAR, the mean S-Cr was $180.7 \pm 99.9 \mu \mathrm{mol} / \mathrm{l}$, in the subgroup with $\mathrm{BL} 154.4 \pm 34.3 \mu \mathrm{mol} / \mathrm{l}$, respectively. Both latter

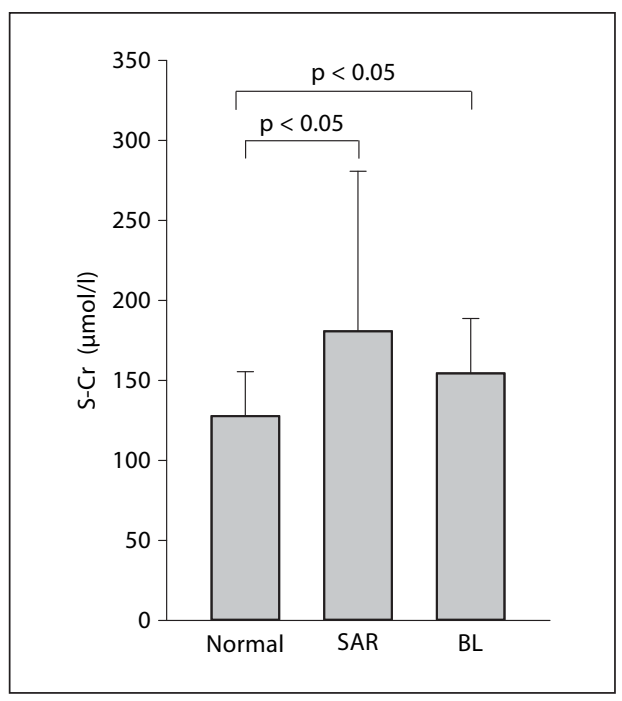

Fig. 1. Mean S-Cr in patients with normal finding, SAR and BL.

values were significantly higher compared to the value of patients with normal finding (fig. 1). In pooled subgroups SAR + BL, the mean value of S-Cr was $168.4 \pm 76.6$ $\mu \mathrm{mol} / \mathrm{l}$ with highly significant difference against the subgroup with normal finding. By the use of ROC analysis, $\mathrm{S}$-Cr $=170 \mu \mathrm{mol} / \mathrm{l}$ was determined as a cut-off point for risk of SAR or BL. Patients with S-Cr $\geq 170 \mu \mathrm{mol} / \mathrm{l} \mathrm{had}$ an odds ratio of 16.3 (95\% CI 5.6-47.9).

\section{HLA Mismatch and PRA}

No significant difference was found between subgroups of patients with normal finding and SAR + BL in the mean number of HLA-A, -B, -DR mismatches ( $3.3 \pm$ 1.2 and $3.6 \pm 1.3$, respectively), and in the mean percentage of maximal PRA $(11.5 \pm 21.6$ and $14.6 \pm 25.1)$.

\section{Intrarenal Gene Expression and Histomorphology at 3-Month Biopsy}

In order to establish the prognostic pattern of potential novel biomarkers, we evaluated the gene expression differences of the selected genes between patients with SAR or BL and normal finding in protocol biopsy. Patients with SAR together with patients with BL revealed higher intrarenal expression of RANTES, IP-10 ( $\mathrm{p}<$ 0.001), C3, CD3, IgJ $(\mathrm{p}<0.01)$ and CD20 $(\mathrm{p}<0.05)$ than the subgroup with normal finding (fig. 2).

The expression of several followed genes correlated significantly with maximal PRA, with the total number of HLA-A, -B, -DR mismatches and with proteinuria at the time of biopsy (table 2). 


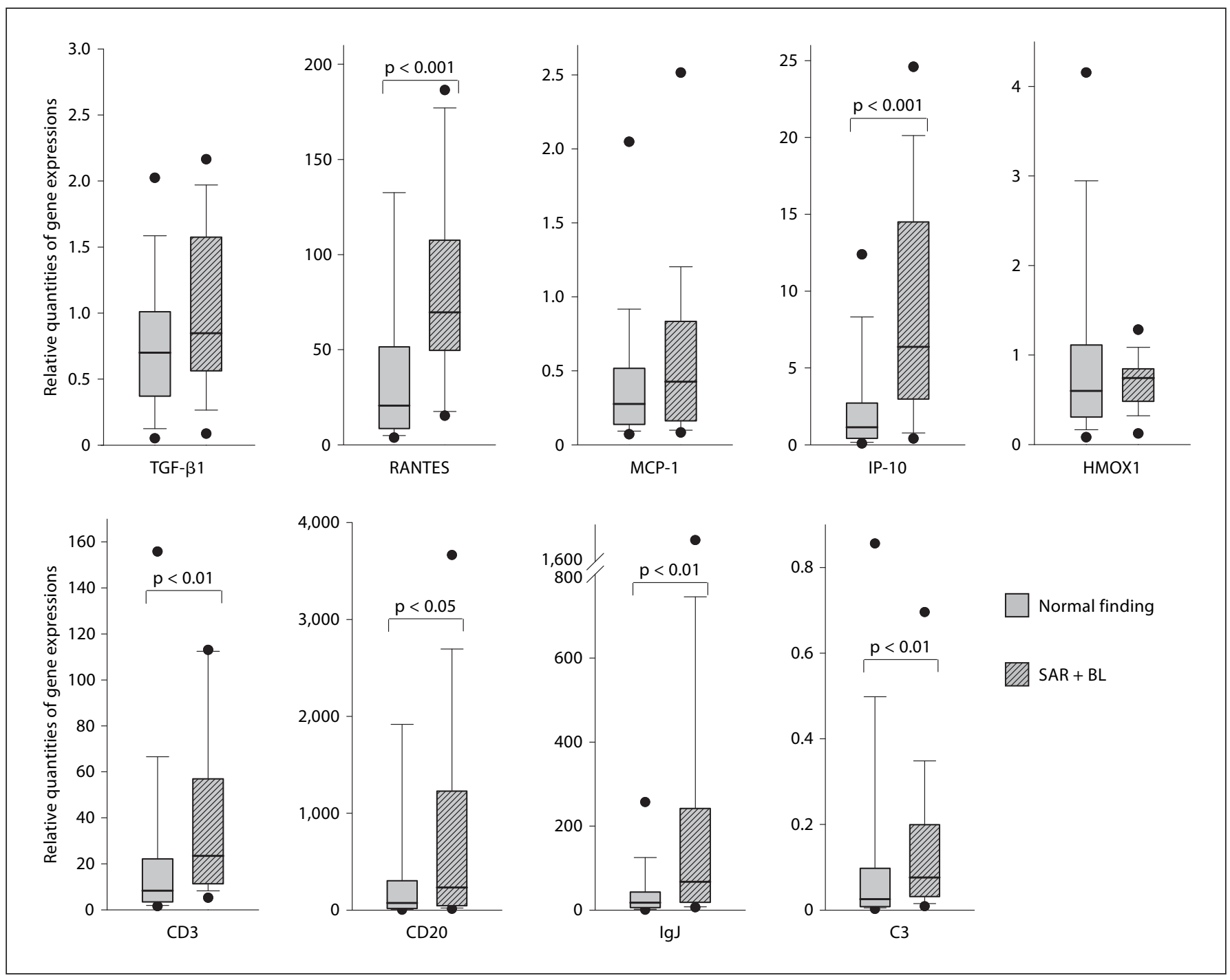

Fig. 2. Quantitative analysis of gene expressions in SAR and BL compared to normal finding. The results are expressed as relative quantities. The box plots show 25th and 75th (boundaries of boxes), 50th (median), 10th and 90th (error bars), 5th and 95th $(\bullet)$ percentile values.

\section{Predictors of $S A R$ and $B L$}

In the multivariate analysis, the statistically independent risk factors (odds ratio with a 95\% CI $>1, \mathrm{p}<0.001$ ) were rejections prior to protocol biopsy: OR 9.19, 95\% CI 3.1-27.3, and S-Cr: OR 10.6, 95\% CI 2.86-39.1. Donor age and PRA were nonsignificant predictors.

\section{Complications after Protocol Biopsy}

There were no serious complications requiring intervention or extending hospitalization. In ultrasound examinations, performed the next day after protocol biopsy, minor complications were observed in 28 patients
(10.9\%): perirenal hematoma in 3 (1.2\%), arteriovenous (A-V) fistula in 21 (8.2\%), and hematoma $+\mathrm{A}-\mathrm{V}$ fistula in $4(1.5 \%)$ patients.

\section{Months' Follow-Up \\ Acute Rejection}

After protocol biopsy, 4/128 patients with a normal finding in protocol biopsy, 2/14 (14.3\%) with SAR, and 2/11 (18.2\%) patients with BL suffered from acute rejection. Incidence of acute rejection after protocol biopsy was significantly higher in patients with SAR $(\mathrm{p}<0.05)$ or BL $(\mathrm{p}<0.05)$ than in patients with a normal finding. 


\section{Graft Loss}

Nine grafts (3.5\%) were lost between 3 and 12 months post-transplant. In the subgroup with normal findings, 2 patients died with functioning graft and one graft was lost due to rejection. In the subgroup with SAR, 3 grafts were lost due to rejection and one after infectious complications. In the subgroup with BL, 1 patient died with functioning graft, and one graft was lost due to rejection. Graft loss occurred significantly more frequently in the subgroup with SAR $(23.5 \%, \mathrm{p}<0.001)$, and nonsignificantly more frequently in the subgroup with BL (15.4\%) compared to the subgroup with normal findings (2.3\%). One of the 8 patients with C4d positivity lost her graft due to rejection and 1 patient died with functioning graft. Other grafts functioned well at 12 months post-transplant.

\section{Serum Creatinine}

The mean values of S-Cr at month 12 did not significantly change since the time of protocol biopsy in all subgroups of patients: normal finding (126.1 \pm 27.4$)$, SAR (194.8 \pm 148.9$)$, and BL (159.4 \pm 64.2$)$. There was no significant difference between the subgroups.

\section{Intrarenal Gene Expression in 3-Month Biopsy and 12} Months' Follow-Up

The expression of MCP-1, IP-10 and C3 correlated with S-Cr 12 months after transplantation ( $\mathrm{p}<0.05)$, but no correlation was found with GFR. Furthermore, intrarenal expression of RANTES, IP-10 ( $p<0.001)$, TGF- $\beta$, CD3, IgJ $(\mathrm{p}<0.01)$, MCP-1 and CD $20(\mathrm{p}<0.05)$ correlated with the total number of biopsy-proven acute rejection episodes within 1 year after transplantation (table 2). As the majority of patients with SAR or BL suffered from acute rejection already before the protocol biopsy, we compared gene expressions in patients who had at least one acute rejection before protocol biopsy with gene expressions in patients with first SAR or BL in protocol biopsy. Patients with repeated rejections had higher expression of IgJ (RQ 279.77 [25.01-2,124.42]) than patients with first rejection (RQ 20.86 [3.37-562.08], p < 0.05), but expression of other genes was comparable in both groups. The expression level did not influence the time to later rejection in patients who suffered from acute rejection after protocol biopsy (data not shown).

There was a significant difference in RANTES and IP10 expression patterns between patients with SAR or BL in protocol biopsy who lost their grafts within one year after transplantation and patients with surviving grafts (table 3). Higher RANTES (RQ $\geq 105$ ) and IP-10 (RQ $\geq 14.5$ ) gene expression in the biopsy revealing SAR or BL
Table 2. Correlation between mRNA expression in the protocol biopsy from available samples and clinical data $(\mathrm{n}=163)$

\begin{tabular}{|c|c|c|c|}
\hline Variable $^{1}$ & Gene & $\mathrm{r}_{\mathrm{s}}$ value $^{2}$ & $\mathrm{p}$ \\
\hline \multirow[t]{4}{*}{ Maximal PRA } & TGF- $\beta 1$ & 0.1737 & $<0.05$ \\
\hline & RANTES & 0.1817 & $<0.05$ \\
\hline & MCP-1 & 0.1791 & $<0.05$ \\
\hline & IP-10 & 0.1833 & $<0.05$ \\
\hline \multirow[t]{6}{*}{ HLA-B mismatches } & RANTES & 0.2127 & $<0.05$ \\
\hline & MCP-1 & 0.2108 & $<0.05$ \\
\hline & IP-10 & 0.2234 & $<0.05$ \\
\hline & IgJ & 0.1493 & NS \\
\hline & $\mathrm{CD} 20$ & 0.2136 & $<0.05$ \\
\hline & C3 & 0.1786 & $<0.05$ \\
\hline \multirow{7}{*}{$\begin{array}{l}\text { Total number of HLA } \\
\text { mismatches }\end{array}$} & RANTES & 0.2648 & $<0.01$ \\
\hline & MCP-1 & 0.2280 & $<0.05$ \\
\hline & IP-10 & 0.2103 & $<0.05$ \\
\hline & IgJ & 0.2098 & $<0.05$ \\
\hline & CD3 & 0.2188 & $<0.05$ \\
\hline & $\mathrm{CD} 20$ & 0.2250 & $<0.05$ \\
\hline & C3 & 0.2403 & $<0.05$ \\
\hline Donor age & MCP-1 & 0.2442 & $<0.01$ \\
\hline \multirow[t]{2}{*}{ MDRD at the time of biopsy } & IP-10 & -0.1901 & $<0.05$ \\
\hline & C3 & -0.2202 & $<0.05$ \\
\hline \multirow{7}{*}{$\begin{array}{l}\text { Proteinuria at the time of } \\
\text { biopsy }\end{array}$} & TGF- $\beta 1$ & 0.2379 & $<0.01$ \\
\hline & RANTES & 0.2288 & $<0.01$ \\
\hline & MCP-1 & 0.1170 & NS \\
\hline & IP-10 & 0.2900 & $<0.01$ \\
\hline & HMOX1 & 0.1920 & $<0.05$ \\
\hline & CD3 & 0.2448 & $<0.01$ \\
\hline & $\mathrm{CD} 20$ & 0.1838 & $<0.05$ \\
\hline \multirow{5}{*}{$\begin{array}{l}\text { Serum creatinine } 12 \text { months } \\
\text { after transplantation }\end{array}$} & $\mathrm{C} 3$ & 0.3025 & $<0.001$ \\
\hline & MCP-1 & 0.2036 & $<0.05$ \\
\hline & IP-10 & 0.1704 & $<0.05$ \\
\hline & CD3 & 0.1773 & NS \\
\hline & C3 & 0.2365 & $<0.05$ \\
\hline \multirow{7}{*}{$\begin{array}{l}\text { Number of acute rejections } \\
\text { within } 12 \text { months after } \\
\text { transplantation }\end{array}$} & TGF- $\beta 1$ & 0.2520 & $<0.01$ \\
\hline & RANTES & 0.2907 & $<0.001$ \\
\hline & MCP-1 & 0.2038 & $<0.05$ \\
\hline & IP-10 & 0.3578 & $<0.001$ \\
\hline & IgJ & 0.2739 & $<0.01$ \\
\hline & CD3 & 0.3020 & $<0.01$ \\
\hline & CD20 & 0.1966 & $<0.05$ \\
\hline
\end{tabular}

\footnotetext{
${ }^{1}$ Only variables where the correlation reached statistical significance for some of the followed genes are mentioned.

${ }^{2}$ Spearman rank correlation coefficient.
} 
Table 3. Comparison of gene expressions between patients with subclinical rejection including borderline changes in protocol biopsy ( $\mathrm{n}=17$ of 163 analyzed samples) who lost grafts within 1 year after transplantation and patients with surviving grafts

\begin{tabular}{lccc}
\hline & $\begin{array}{l}\text { Failed grafts after SAR } \\
\text { or BL }(\mathrm{n}=4)\end{array}$ & $\begin{array}{l}\text { Surviving grafts after } \\
\text { SAR or BL }(\mathrm{n}=13)\end{array}$ & $\mathrm{p}$ \\
\hline TGF- $\beta 1$ & $1.31[0.53-2.24]$ & $0.83[0.01-2.02]$ & $\mathrm{NS}$ \\
RANTES & $145.89[56.51-178.68]$ & $68.85[15.25-190.50]$ & $<0.1$ \\
MCP-1 & $0.48[0.10-0.84]$ & $0.36[0.08-3.21]$ & $\mathrm{NS}$ \\
IP-10 & $17.96[5.82-26.36]$ & $5.51[0.22-15.40]$ & $<0.05$ \\
HMOX1 & $0.68[0.36-1.38]$ & $0.74[0.02-1.11]$ & $\mathrm{NS}$ \\
CD3 & $24.83[23.43-107.21]$ & $16.33[4.23-113.27]$ & $\mathrm{NS}$ \\
CD20 & $539.34[29.87-2,718.31]$ & $232.16[9.11-4,174.03]$ & $\mathrm{NS}$ \\
IgJ & $108.65[21.52-791.81]$ & $48.17[6.14-2,124.42]$ & $\mathrm{NS}$ \\
C3 & $0.13[0.03-0.23]$ & $0.07[0.01-0.84]$ & $\mathrm{NS}$ \\
\hline
\end{tabular}

Table 4. Variables associated with kidney graft failure within 12 months after transplantation by multivariate logistic regression analysis $(\mathrm{n}=163)$

\begin{tabular}{lcccc}
\hline Variable & $\begin{array}{l}\text { Coeffi- } \\
\text { cient }\end{array}$ & $\begin{array}{l}\text { Odds } \\
\text { ratio }\end{array}$ & $95 \%$ CI & $\mathrm{p}$ \\
\hline $\begin{array}{l}\text { Donor age } \\
\begin{array}{l}\text { Tacrolimus-based } \\
\text { immunosuppression }\end{array}\end{array}$ & -0.094 & 0.910 & $0.856-0.967$ & 0.0007 \\
$\begin{array}{l}\text { MDRD at the time } \\
\text { of biopsy }\end{array}$ & -4.633 & 0.010 & $0.0002-0.451$ & 0.0079 \\
\hline
\end{tabular}

implied an increased risk for renal graft failure within the next 12 months after biopsy (OR 36, 95\% CI 1.7-757.8, $\mathrm{p}<0.05)$. Logistic regression analysis in the whole cohort of patients, however, did not confirm the influence of intrarenal expression levels of RANTES and IP-10 on the 1-year follow-up (table 4).

\section{Discussion}

Incidence of post-transplant acute rejection rates significantly decreased over the last decade and reached values under $20 \%$ in the low-risk patient cohorts [15]. New immunosuppressive agents and powerful immunosuppressive regimens are generally assumed as the reason for such a decrease. Incidence of SAR in protocol biopsies is highest early after transplantation and decreases over the long term [16]. In protocol biopsies at 3 months after transplantation, the prevalence of SAR + BL in six pub- lished studies on cohorts of more than 30 patients $[1,2$, 17-20] was between a wide range of $10-78 \%$. It is believed that the prevalence of early subclinical rejection is influenced by the use of antibody induction and by the type of maintenance immunosuppression [21]. In our study, subclinical rejection including borderline changes occurred in $12.4 \%$. This frequency is rather low and comparable with others $[17,18]$. In $8 \%$ of samples, C4d positivity was found. Detection of $\mathrm{C} 4 \mathrm{~d}$ is rather a new procedure, and antibody-mediated rejection was included into the Banff classification in 2003 [13]. In 6 cited studies [1, 2, 16-19] of protocol biopsy at three months after transplantation, $\mathrm{C} 4 \mathrm{~d}$ prevalence is not mentioned. The prevalence of $\mathrm{C} 4 \mathrm{~d}$ positivity in two studies with early protocol biopsy as early as 7 days after transplantation $[22,23]$ was rather high (30 and 13\%, respectively), and mostly associated with acute antibody-mediated rejection. More than one half of the samples were free of any pathological changes. The most similar finding to our study was $43 \%$ in a study with 282 protocol biopsies [19].

In most studies, with one exception [3], acute rejections prior to protocol biopsy were an important risk factor for SAR [16, 24-26]. In our study, $84.4 \%$ of patients with SAR + BL had acute rejection and this finding confirms acute rejection prior to protocol biopsy as a significant risk factor for SAR + BL. Large multicentric studies demonstrated a lower incidence of acute rejections in regimens with tacrolimus compared to cyclosporine [27, 28], and, similarly, such a difference among regimens was found in the incidence of SAR $[29,30]$. Our results did not show any difference in prevalence of SAR + BL between the groups of patients treated with regimens based on cyclosporine or tacrolimus. This lack of difference might be due to the low number of patients treated with the cyclosporine-based regimen.

The mean value of S-Cr was significantly higher in patients with SAR + BL than in patients with normal finding in $\mathrm{PB}$, although patients indicated to $\mathrm{PB}$ had stabilized values of S-Cr. We showed that patients with S-Cr $\geq 170 \mu \mathrm{mol} / \mathrm{l}$ are at risk of SAR $+\mathrm{BL}$ development $(\mathrm{OR}=$ 16.3 ), and this finding has a $95.5 \%$ specificity, but rather low sensitivity (47.7\%). The significance of this finding was confirmed by multivariate analysis.

Surprisingly, our results did not show any difference in total HLA mismatches between patients with normal finding and SAR + BL in PB. HLA mismatch was found to be a risk factor for SAR when DR mismatches [24, 31] or total HLA mismatch [1] were studied, but in another study [3] the association between total HLA or separate DR mismatch and SAR was not described. 
A 12-month follow-up showed that in our patients, SAR and BL were risk factors for late rejections and SAR was a risk factor for graft loss, although all patients with SAR, and the majority of patients with BL were treated with methylprednisolone. A prospective controlled study [2] proved that SAR treated with methylprednisolone at 3 months after transplantation is associated with lower creatinine and a lower incidence of acute rejection over the following 2 years. Our results did not compare the further outcome of treated and non-treated SAR, but they show that even treated SAR has a worse further outcome in comparison to patients with normal finding in protocol biopsy. This finding may be in concordance with another study [18] where persistent rejection was present in follow-up biopsies after treated SAR. A significant association between subclinical rejection at three months and severity of chronic allograft nephropathy at 12 months was reported [1]. In comparison, untreated SAR in protocol biopsy at 6 and 12 months was not associated with progressive loss of graft function up to 2 years [3]. However, some authors still consider it necessary for a large controlled study to justify indication of SAR treatment [32]. Furthermore, some authors treat both SAR and BL [16].

The absence of serious complication after protocol biopsy proved the safety of this procedure. The most frequent complication, A-V fistula, in $8.6 \%$ of patients is comparable with $10 \%$ found in a large study focused on complications after biopsy [33]. Based on this experience, protocol biopsy has become the routine method in our center.

Complex graft injuries in acute rejections of kidney allografts are caused by infiltrating cells producing a broad spectrum of cytokines, chemokines and other molecules $[34,35]$. Subclinical acute rejection is also accompanied by an enhanced expression of immune activation markers [36-38]. In our study, we found an augmented expression of chemokines RANTES and IP-10, marker of $\mathrm{B}$ cells and plasma cells CD20 and IgJ, respectively, and a
C3 complement component in subclinical rejection including borderline changes. We found, however, only enhanced expression of MCP-1, IP-10 and C3 in protocol biopsy which correlated with renal function deterioration at 1 year after kidney transplantation. Some authors found that acute rejection with dense aggregates of CD20+ cells at the time of biopsy was strongly associated with glucocorticoid resistance and poor graft outcomes [39, 40]. In our study, however, we did not find heightened CD20 expression to be linked with worse graft outcome within 12 months after transplantation. This is in line with our recent report showing higher B cells transcripts during early acute rejection to be associated with a better prognosis [12]. Moreover, recently it is assumed that molecular phenotypes of various diseases with broad forms of manifestation, such as allograft rejection, might allow for determining which patients are at risk for disease progression [41, 42].

In our study we found high expression of chemokines RANTES and IP-10 in subclinical rejection including borderline changes to be associated with a higher risk of premature graft failure. In the multivariate analysis, however, expression of those genes was not predictable for graft loss, and renal graft function was shown to have a stronger effect. This might indeed be influenced by the small number of patients suffering from subclinical rejection. To confirm our observation, larger multicenter studies with longer follow-up are warranted. Clinically, the most relevant observation from our study is the relativity of 'stable' but abnormal renal graft function. Patients with stable S-Cr above $170 \mu \mathrm{mol} / \mathrm{l}$ warrant frequent monitoring since it might be associated with unrecognized rejection and the risk for premature graft failure.

\section{Acknowledgements}

The authors thank Dr. Vera Lanska and Mgr Jelena Skibova for statistical analysis and patients and nurses for their help with the study. Funding received from Internal Grant Agency from the Czech Ministry of Health, No. NR8897-4.

\section{References}

1 Nankivell BJ, Fenton-Lee CA, Kuypers DR, Cheung E, Allen RD, O'Connell PJ, Chapman JR: Effect of histological damage on long-term kidney transplant outcome. Transplantation 2001;71:515-523.

-2 Rush D, Nickerson P, Gough J, McKenna R, Grimm P, Cheang M, Trpkov K, Solez K, Jeffery J: Beneficial effects of treatment of early subclinical rejection: a randomized study. J Am Soc Nephrol 1998;9:2129-2134.
Scholten EM, Rowshani AT, Cremers S, Bemelman FJ, Eikmans M, van Kan E, Mallat MJ, Florquin S, Surachno J, ten Berge IJ, Bajema IM, de Fijter JW: Untreated rejection in 6-month protocol biopsies is not associated with fibrosis in serial biopsies or with loss of graft function. J Am Soc Nephrol 2006;17:2622-2632.
4 Halloran PF: Call for revolution: a new approach to describing allograft deterioration. Am J Transplant 2002;2:195-200.

$\checkmark 5$ Chapman JR, O'Connell PJ, Nankivell BJ: Chronic renal allograft dysfunction. J Am Soc Nephrol 2005;16:3015-3026.

-6 Tullius SG, Tilney NL: Both alloantigen-dependent and -independent factors influence chronic allograft rejection. Transplantation 1995;59:313-318. 
7 Baan CC, Weimar W: Intragraft cytokine gene expression: implications for clinical transplantation. Transplant Int 1998;11:169180.

$>8$ Hribova P, Kotsch K, Brabcova I, Vitko S, Volk HD, Lacha J: Cytokines and chemokine gene expression in human kidney transplantation. Transplant Proc 2005;37:760-763.

$\checkmark 9$ Melk A, Henne T, Kollmar T, Strehlau J, Latta K, Offner G, Jhangri GS, Ehrich JH, Von Schnakenburg C: Cytokine single nucleotide polymorphisms and intrarenal gene expression in chronic allograft nephropathy in children. Kidney Int 2003;64:314-320.

10 Hribova P, Lacha J, Kotsch K, Volk HD, Brabcova I, Skibova J, Vitko S, Viklicky O: Intrarenal cytokine and chemokine gene expression and kidney graft outcome. Kidney Blood Press Res 2007;30:273-282.

-11 Pribylova-Hribova P, Kotsch K, Lodererova A, Viklicky O, Vitko S, Volk HD, Lacha J: TGF-betal mRNA upregulation influences chronic renal allograft dysfunction. Kidney Int 2006;69:1872-1879.

12 Viklicky O, Hribova P, Volk HD, Slatinska J, Petrasek J, Bandur S, Honsova E, Reinke P: Molecular phenotypes of acute rejection predict kidney graft prognosis. J Am Soc Nephrol 2009; in press.

$\checkmark 13$ Racusen LC, Colvin RB, Solez K, Mihatsch MJ, Halloran PF, Campbell PM, Cecka MJ, Cosyns JP, Demetris AJ, Fishbein MC, Fogo A, Furness P, Gibson IW, Glotz D, Hayry P, Hunsickern L, Kashgarian M, Kerman R, Magil AJ, Montgomery R, Morozumi K, Nickeleit V, Randhawa P, Regele H, Seron D, Seshan S, Sund S, Trpkov K: Antibody-mediated rejection criteria - an addition to the Banff 97 classification of renal allograft rejection. Am J Transplant 2003;3:708-714.

14 Solez K, Colvin RB, Racusen LC, Sis B, Halloran PF, Birk PE, Campbell PM, Cascalho M, Collins AB, Demetris AJ, Drachenberg CB, Gibson IW, Grimm PC, Haas M, Lerut E, Liapis H, Mannon RB, Marcus PB, Mengel M, Mihatsch MJ, Nankivell BJ, Nickeleit V, Papadimitriou JC, Platt JL, Randhawa P, Roberts I, Salinas-Madriga L, Salomon DR, Seron D, Sheaff M, Weening JJ: Banff '05 Meeting Report: differential diagnosis of chronic allograft injury and elimination of chronic allograft nephropathy ('CAN'). Am J Transplant 2007;7:518-526.

15 Vincenti F: A decade of progress in kidney transplantation. Transplantation 2004;77: S52-S61.

16 Nankivell BJ, Chapman JR: The significance of subclinical rejection and the value of protocol biopsies. Am J Transplant 2006;6: 2006-2012.

-17 Helantera I, Ortiz F, Helin H, Raisanen-Sokolowski A, Honkanen E, Koskinen P: Timing and value of protocol biopsies in wellmatched kidney transplant recipients: a clinical and histopathologic analysis. Transplant Int 2007;20:982-990.

-18 Kee TY, Chapman JR, O’Connell PJ, Fung CL, Allen RD, Kable K, Vitalone MJ, Nan- kivell BJ: Treatment of subclinical rejection diagnosed by protocol biopsy of kidney transplants. Transplantation 2006;82:3642.

19 Seron D, Moreso F, Ramon JM, Hueso M, Condom E, Fulladosa X, Bover J, Gil-Vernet S, Castelao AM, Alsina J, Grinyo JM: Protocol renal allograft biopsies and the design of clinical trials aimed to prevent or treat chronic allograft nephropathy. Transplantation 2000;69:1849-1855.

20 Tichy T, Tichy M, Zadrazil J, Krejci K, Horcicka V Jr, al-Jabry S, Bachleda P, Kral V, Dusek J: Histologic findings in protocol biopsies of transplanted kidneys. Cesk Patol 2003;39:11-16.

21 Rush D: Protocol transplant biopsies: an underutilized tool in kidney transplantation. Clin J Am Soc Nephrol 2006;1:138-143.

22 Koo DD, Roberts IS, Quiroga I, Procter J, Barnardo MC, Sutton M, Cerundolo L, Davies DR, Friend PJ, Morris PJ, Fuggle SV: C4d deposition in early renal allograft protocol biopsies. Transplantation 2004;78:398-403.

23 Sund S, Hovig T, Reisaeter AV, Scott H, Bentdal O, Mollnes TE: Complement activation in early protocol kidney graft biopsies after living-donor transplantation. Transplantation 2003;75:1204-1213.

24 Choi BS, Shin MJ, Shin SJ, Kim YS, Choi YJ, Kim YS, Moon IS, Kim SY, Koh YB, Bang BK, Yang CW: Clinical significance of an early protocol biopsy in living-donor renal transplantation: ten-year experience at a single center. Am J Transplant 2005;5:1354-1360.

25 Kanetsuna Y, Yamaguchi Y, Toma H, Tanabe $\mathrm{K}$ : Histological evaluation of renal allograft protocol biopsies in the early period and 1 year after transplantation. Clin Transplant 2003;17(suppl 10):25-29.

26 Mengel M, Gwinner W, Schwarz A, Bajeski R, Franz I, Brocker V, Becker T, Neipp M, Klempnauer J, Haller H, Kreipe H: Infiltrates in protocol biopsies from renal allografts. Am J Transplant 2007;7:356-365

27 Margreiter R: Efficacy and safety of tacrolimus compared with ciclosporin microemulsion in renal transplantation: a randomised multicentre study. Lancet 2002;359:741746.

28 Pirsch JD, Miller J, Deierhoi MH, Vincenti F, Filo RS: A comparison of tacrolimus (FK506) and cyclosporine for immunosuppression after cadaveric renal transplantation. FK506 Kidney Transplant Study Group. Transplantation 1997;63:977-983.

29 Gloor JM, Cohen AJ, Lager DJ, Grande JP, Fidler ME, Velosa JA, Larson TS, Schwab TR, Griffin MD, Prieto M, Nyberg SL, Sterioff S, Kremers WK, Stegall MD: Subclinical rejection in tacrolimus-treated renal transplant recipients. Transplantation 2002;73:19651968.

>30 Moreso F, Alperovich G, Fulladosa X, GilVernet S, Ibernon M, Carrera M, Castelao AM, Hueso M, Grinyo JM, Seron D: Histologic findings in protocol biopsies performed in stable renal allografts under different im- munosuppressive schedules. Transplant Proc 2003;35:1666-1668.

31 Rush DN, Jeffery J, Gough J, Grimm P, Lipman M, Birk P, McKenna R, Nickerson P: Predicting rejection: is early diagnosis achievable and important? Graft 1999;2:31.

32 Bohmig GA, Regele H, Horl WH: Protocol biopsies after kidney transplantation. Transplant Int 2005;18:131-139.

33 Furness PN, Philpott CM, Chorbadjian MT, Nicholson ML, Bosmans JL, Corthouts BL, Bogers JJ, Schwarz A, Gwinner W, Haller H, Mengel M, Seron D, Moreso F, Canas C: Protocol biopsy of the stable renal transplant: a multicenter study of methods and complication rates. Transplantation 2003;76:969-973.

-34 Flechner SM, Kurian SM, Head SR, Sharp SM, Whisenant TC, Zhang J, Chismar JD, Horvath S, Mondala T, Gilmartin T, Cook DJ, Kay SA, Walker JR, Salomon DR: Kidney transplant rejection and tissue injury by gene profiling of biopsies and peripheral blood lymphocytes. Am J Transplant 2004;4:14751489.

35 Strehlau J, Pavlakis M, Lipman M, Shapiro M, Vasconcellos L, Harmon W, Strom TB: Quantitative detection of immune activation transcripts as a diagnostic tool in kidney transplantation. Proc Natl Acad Sci USA 1997;94:695-700.

36 Kirk AD, Jacobson LM, Heisey DM, Radke NF, Pirsch JD, Sollinger HW: Clinically stable human renal allografts contain histological and RNA-based findings that correlate with deteriorating graft function. Transplantation 1999;68:1578-1582

37 Lipman ML, Shen Y, Jeffery JR, Gough J, McKenna RM, Grimm PC, Rush DN: Immune-activation gene expression in clinically stable renal allograft biopsies: molecular evidence for subclinical rejection. Transplantation 1998;66:1673-1681.

38 Veronese FV, Noronha IL, Manfro RC, Edelweiss MI, Goldberg J, Goncalves LF: Prevalence and immunohistochemical findings of subclinical kidney allograft rejection and its association with graft outcome. Clin Transplant 2004; 18:357-364.

>39 Sarwal M, Chua MS, Kambham N, Hsieh SC, Satterwhite T, Masek M, Salvatierra O Jr: Molecular heterogeneity in acute renal allograft rejection identified by DNA microarray profiling. N Engl J Med 2003;349:125138.

40 Tsai EW, Rianthavorn P, Gjertson DW, Wallace WD, Reed EF, Ettenger RB: CD20+ lymphocytes in renal allografts are associated with poor graft survival in pediatric patients. Transplantation 2006;82:1769-1773.

41 Itadani H, Mizuarai S, Kotani H: Can systems biology understand pathway activation? Gene expression signatures as surrogate markers for understanding the complexity of pathway activation. Curr Genomics 2008;9:349-360.

42 Schmid H, Henger A, Kretzler M: Molecular approaches to chronic kidney disease. Curr Opin Nephrol Hypertens 2006;15:123-129. 